\title{
FAKTOR-FAKTOR YANG MEMENGARUHI PRODUKSI KOPI DI DESA KERTAMANDALA KECAMATAN PANJALU KABUPATEN CIAMIS
}

\section{FACTORS AFFECTING COFFEE PRODUCTION IN KERTAMANDALA VILLAGE PANJALU DISTRICT CIAMIS REGENCY}

\author{
YENI ANGGRAENI ${ }^{*}$, IWAN SETIAWAN ${ }^{2}$, AGUS YUNIAWAN ISYANTO ${ }^{1}$ \\ ${ }^{1}$ Fakultas Pertanian Universitas Galuh \\ ${ }^{2}$ Fakultas Pertanian Universitas Padjajaran \\ *Email: anggraeniyeni575@gmail.com
}

\begin{abstract}
ABSTRAK
Desa Kertamandala merupakan daerah yang paling banyak menanam kopi robusta jika dibandingkan dengan daerah lainnya di Kecamatan Panjalu. Walaupun permintaan global dan pasar domestik cukup besar, produktivitas kopi masih sulit untuk ditingkatkan. Tujuan penelitian ini adalah untuk mengetahui apa saja faktor-faktor yang memengaruhi produksi kopi robusta di Desa Kertamandala. Penelitian ini merupakan penelitian kuantitatif dan metode penelitian suatu kasus pada usahatani kopi di Desa Kertamandala Kecamatan Panjalu dengan teknik penarikan sampel menggunakan simple random sampling dan penentuan sampel menggunakan rumus Slovin dengan tingkat kesalahan 15 persen, hasil penghitungan yang diperoleh adalah 44 petani dari 225 petani. Data yang dikumpulkan berupa data primer dan sekunder. Faktor-faktor yang memengaruhi produksi kopi robusta di Desa Kertamandala adalah luas tanah, jumlah tenaga kerja, umur tanaman, dan jumlah pupuk, baik secara simultan maupun parsial. Cara untuk meningkatkan produksi kopi robusta yaitu para petani harus mengoptimalkan penggunaan tenaga kerja, mengurangi pupuk agar tidak berlebihan yang dapat mengurangi kesuburan tanah, dan intensifikasi lahan.
\end{abstract}

Kata Kunci: Produksi kopi, fungsi produksi, faktor-faktor

\begin{abstract}
Kertamandala Village is the area that grows the most Robusta coffee compared to other areas in Panjalu District. However, productivity of coffee production system in Kertamandala Village is still difficult to increase despite the large global demand and the domestic market. This research has the aim to find out the production factors which influence Robusta coffee production in Kertamandala Village. The type of research used is a quantitative research and research methods was conducted using of a case method in Kertamandala Village of Panjalu District with a sampling technique using simple random sampling and determination of the sample using the Slovin with an error rate of 15 percent, the calculation results obtained were 44 farmers from 225 farmers. The data collected in this study are primary data and secondary data. The factors that influence the production in Kertamandala Village are the width of the land, the workers, age of plants, and the fertilizer, simultaneously or partially. The recommendation for improving the production of the robusta coffee are the farmers must do optimizing the use of manpower, reducing the unnecessary fertilizer which can cause infertility of the land, and land intensification.
\end{abstract}

Keywords: Coffee production, production function, factors

\section{PENDAHULUAN}

Kopi merupakan komoditas hasil pertanian yang sangat akrab dengan masyarakat, mulai dari kalangan ekonomi atas sampai bawah. Hingga sekarang, kopi tetap menduduki komoditas andalan ekspor hasil pertanian Indonesia selain karet kakao, sawit dan kelapa. Kopi merupakan 
salah satu komoditi perkebunan yang diharapkan mampu meningkatkan nilai devisa ekspor Indonesia (Santoso, 2016).

Menurut Badan Pusat Statistik (2018), Provinsi Jawa Barat merupakan salah satu provinsi di Indonesia yang termasuk ke dalam 10 besar provinsi yang memiliki perkebunan kopi yang luas, yaitu sebesar 41.300 hektar atau 3,33 persen dari total luas perkebunan kopi di Indonesia dengan produksi sebesar 19.600 ton atau 2,71 persen total produksi kopi di Indonesia.

Kebutuhan kopi di Jawa Barat mencapai 90.000 ton setiap tahun, pola konsumsi ini tidak seimbang dengan jumlah produksi kopi di Jawa Barat yang hanya mencapai 19.600 ton pada tahun 2018.

Pemerintah Provinsi Jawa Barat masih terus berupaya untuk meningkatkan produksi kopinya, mulai dari penyaluran dana, transfer teknologi, pemberian penyuluhan kepada masyarakat dan lainlain. Namun demikian, karena berbagai kendala, upaya yang dilakukan belum maksimal terutama untuk mencapai daerah terpencil, akibatnya banyak usahatani kopi yang telah berkembang dan ada juga yang belum berkembang.

Kabupaten Ciamis merupakan daerah yang memiliki potensi ekonomi yang cukup tinggi, terutama pada sektor pertanian. Sehingga paradigma pembangunan ekonomi di Kabupaten Ciamis dititikberatkan pada keselarasan pengembangan pertanian dengan bertumpu pada pengembangan sumber daya lokal. Perkebunan kopi robusta menjadi salah satu sektor pertanian yang berpotensi di Kabupaten Ciamis.

Kecamatan Panjalu termasuk kawasan agropolitan di Kabupaten Ciamis karena memiliki pengembangan yang baik dalam sektor pertanian, sehingga menghasilkan komoditas unggulan padi sawah dan sayuran. Selain itu, sektor kehutanan, perkebunan dan peternakan di Kecamatan Panjalu sangat maju. Salah satu produksi terbesar dalam sektor perkebunan di Kecamatan Panjalu adalah kopi robusta.

Menurut Dinas Pertanian Kabupaten Ciamis (2019), luas lahan kopi robusta pada tahun 2018 di Kecamatan Panjalu yaitu 207,27 hektar dengan jumlah produksi 98,81 ton, dan produktivitas 0,85 ton per hektar.

Budidaya kopi robusta di Kecamatan Panjalu dilaksanakan di 8 desa dengan lahan di dalam kawasan seluas 401,9 ha dan di luar kawasan seluas 83 ha, produksi cherry $380.030 \mathrm{~kg}$, rata-rata produktivitas $336,09 \mathrm{~kg} / \mathrm{ha}$, dan jumlah petani 489 orang. 
Desa Kertamandala merupakan daerah yang paling banyak menanam kopi robusta jika dibandingkan dengan daerah lainnya di Kecamatan Panjalu. Usaha perkebunan kopi di Desa Kertamandala bukan asli berasal dari masyarakat Desa Kertamandala, karena dimulai oleh pendatang. Seiring berjalannya waktu, banyak masyarakat Desa Kertamandala yang mulai tertarik dengan usahatani kopi robusta.

Menurut Badan Penyuluhan Pertanian Kecamatan Panjalu (2020), produktivitas usahatani kopi robusta di Kecamatan Panjalu sebesar 336,09 kg/ha, sedangkan produktivitas usahatani kopi robusta di Desa Kertamandala sebesar $810,98 \mathrm{~kg} / \mathrm{ha}$. Produktivitas ini lebih rendah dibandingkan dengan produktivitas kopi robusta di Kecamatan Panti Kabupaten Jember sebesar $1.130 \mathrm{~kg} / \mathrm{ha}$ (Abimanyu dkk., 2018) dan produktivitas kopi robusta di Provinsi Jawa Tengah sebesar $1.120 \mathrm{~kg} / \mathrm{ha}$ (Isyariansyah dkk., 2018). Rendahnya produktivitas ini diduga dipengaruhi oleh penggunaan faktor-faktor produksi.

Sistem produksi kopi di Desa Kertamandala masih tradisional, dan keterbatasan modal dalam pemenuhan teknologi untuk meningkatkan produksi, sehingga produktivitas kopi masih sulit ditingkatkan walaupun permintaan pasar domestik dan global cukup besar.

Produksi merupakan kegiatan memproses input menjadi output. Produksi mempunyai landasan teknis yang di dalam teori ekonomi disebut fungsi produksi, yaitu hubungan antara faktor-faktor produksi dan tingkat produksi yang diciptakannya seperti tenaga kerja, modal, serta teknologi yang mendukung dalam proses produksi (Sukirno, 2005).

Penelitian ini bertujuan untuk mengetahui faktor-faktor yang memengaruhi produksi kopi di Desa Kertamandala Kecamatan Panjalu

\section{METODE PENELITIAN}

Penelitian ini merupakan penelitian kuantitatif pada usahatani kopi di Desa Kertamandala Kecamatan Panjalu. Menurut Sugiyono (2014), metode penelitian kuantitatif merupakan metode penelitian berlandaskan pada filsafat positivisme yang digunakan untuk meneliti sampel atau populasi tertentu, data dikumpulkan menggunakan instrumen penelitian, dan analisis data berupa statistik bertujuan untuk menguji hipotesis yang telah ditetapkan.

Dalam penelitian ini, definisi operasional variabel yang digunakan adalah sebagai berikut: 
1. Variabel Input

a. Luas lahan adalah lahan yang diusahakan oleh setiap petani kopi yang dinyatakan dalam satuan hektar (ha).

b. Jumlah Tenaga kerja adalah jumlah tenaga kerja yang mengolah perkebunan kopi yang dinyatakan dalam satuan orang/hari.

c. Umur Tanaman adalah umur tanaman kopi yang dimiliki oleh setiap petani terhitung mulai ditanam di lahan dinyatakan dalam satuan tahun (th).

d. Jumlah Pupuk adalah jumlah pupuk yang digunakan untuk pemeliharaan kopi yang dinyatakan dalam satuan kilogram per hektar (kg/ha).

2. Produksi adalah produksi kopi yang diperoleh dari usaha perkebunan kopi yang dinyatakan dalam satuan kilogram per hektar (kg/ha).

Data yang dikumpulkan dalam penelitian ini berupa data primer dan sekunder. Data primer merupakan data yang didapat sendiri dengan melakukan pengamatan secara langsung ke lokasi penelitian serta hasil wawancara terhadap responden (dengan panduan kuesioner). Data sekunder diperoleh dengan teknik dokumentasi, yaitu teknik pengumpulan data yang berasal dari berbagai arsip tertulis yang dimiliki oleh instansi-instansi terkait penelitian (Abdurrahman dan Muhidin, 2011).

Jumlah petani kopi di Desa Kertamandala sebanyak 225 orang. Penentuan sampel menggunakan rumus Slovin dengan tingkat kesalahan 15 persen, maka diperoleh ukuran sampel sebanyak 44 orang (petani kopi). Penentuan sampel dilakukan dengan menggunakan acak sederhana (simple random sampling). Menurut Sugiyono (2014), acak sederhana merupakan pengambilan anggota sampel dari populasi yang dilakukan dengan cara acak tanpa memperhatikan lapisan yang ada dalam populasi itu.

Pendugaan fungsi produksi dilakukan dengan menggunakan fungsi produksi Cobb-Douglas dengan persamaan sebagai berikut:

$Y=\beta o+\beta_{1} X_{1}+\beta_{2} X_{2}+\beta_{3} X_{3}+\beta_{4} X_{4}+e$

Dimana:

$$
\begin{array}{ll}
\mathrm{Y} & =\text { Produksi kopi }(\mathrm{kg}) \\
\beta_{0} & =\text { Intersep/konstanta } \\
\beta & =\text { Koefisien regresi } \\
\mathrm{X}_{1} & =\text { Luas lahan (ha) } \\
\mathrm{X}_{2} & =\text { Jumlah tenaga Kerja (orang) } \\
\mathrm{X}_{3} & =\text { Umur tanaman (tahun) } \\
\mathrm{X}_{4} & =\text { Jumlah pupuk (kg) } \\
\mathrm{e} & =\text { Error term } \\
& \text { pendugaan parameter fungsi } \\
\text { produksi dan faktor-faktor yang }
\end{array}
$$


memengaruhi produksi kopi dilakukan dengan menggunakan SPSS versi 25.

\section{HASIL DAN PEMBAHASAN}

Sebelum dilakukan uji regresi linier berganda terhadap hipotesis penelitian, maka terlebih dahulu dilakukan pengujian untuk mengetahui ada tidaknya pelanggaran terhadap asumsi-asumsi klasik.
Dari hasil uji asumsi klasik dapat disimpulkan bahwa seluruh asumsi klasik telah terpenuhi yaitu tidak terdapat gejala normalitas, multikolinieritas, heteroskedastisitas maupun autokorelasi. Oleh karena itu, persyaratan untuk melakukan analisis regresi linier berganda telah terpenuhi.

Hasil analisis regresi linier berganda dapat dilihat pada Tabel 1 .

Tabel 1. Faktor-faktor yang Memengaruhi Produksi Kopi Robusta

\begin{tabular}{|c|c|c|c|c|c|c|}
\hline \multicolumn{7}{|c|}{ Coefficients $^{\mathrm{a}}$} \\
\hline & & Unstan & ardized & Standardized & & \\
\hline \multicolumn{2}{|c|}{ Model } & B & Std. Error & Beta & $\mathrm{T}$ & Sig. \\
\hline \multirow[t]{5}{*}{1} & (Constant) & 3,988 & 0,790 & & 5,047 &, 000 \\
\hline & Luas Lahan & 0,739 & 0,067 & 0,724 & 10,948 & ,000 \\
\hline & Jumlah Tenaga Kerja & 0,286 & 0,110 & 0,127 & 2,589 & ,013 \\
\hline & Umur Tanaman & 0,574 & 0,156 & 0,143 & 3,691 & 001 \\
\hline & Jumlah Pupuk & 0,198 & 0,079 & 0,140 & 2,513 &, 016 \\
\hline \multicolumn{7}{|c|}{$\mathrm{R}=0,977$} \\
\hline \multicolumn{7}{|c|}{$\mathrm{R}^{2}=0,955$} \\
\hline \multicolumn{7}{|c|}{$\mathrm{F}=204,999$} \\
\hline
\end{tabular}

Sumber: Analisis Data Primer, 2020

Nilai koefisien determinasi $\left(\mathrm{R}^{2}\right)$ sebesar 0,955 atau 95,5 persen menunjukkan bahwa keragaman hasil produksi kopi dapat dijelaskan oleh faktorfaktor produksi luas lahan, jumlah tenaga kerja, umur tanaman dan jumlah pupuk, sehingga fungsi produksi cukup baik digunakan untuk mengetahui hubungan antara faktor produksi dengan hasil produksi kopi di Desa Kertamandala.
Sisanya yaitu 4,5 persen dijelaskan oleh variabel lainnya.

Nilai $F_{\text {hitung }}$ sebesar 204,999 dengan nilai $F_{\text {tabel }}$ adalah 2,61 sehingga nilai $F_{\text {hitung }}$ $>\mathrm{F}_{\text {tabel }}$ atau 204,999 > 2,6, dan tingkat signifikasi juga menunjukan 0,000 lebih kecil dari 0,05 sehingga dapat disimpulkan bahwa luas lahan, jumlah tenaga kerja, umur tanaman, dan jumlah pupuk secara simultan berpengaruh signifikan terhadap 
produksi kopi di Desa Kertamandala.

Luas lahan dengan variabel produksi kopi menunjukkan nilai $t$ hitung sebesar 10,948 koefisien regresi sebesar 0,739 , dan nilai probabilitas sebesar 0,000 yang lebih kecil dari 0,05, hal ini menunjukan bahwa luas lahan berpengaruh positif dan signifikan terhadap produksi kopi, dan nilai t hitung sebesar 10,948 lebih besar dari t tabel sebesar 2,02269 sehingga dapat disimpulkan bahwa luas lahan berpengaruh signifikan. Hal ini sejalan dengan penelitian Isyanto (2012), Risandewi (2013), Fatma (2011), Ratih dan Harmini (2012), yang menunjukkan bahwa semakin luas lahan yang digunakan dapat meningkatkan hasil produksi. Hal tersebut diduga karena lahan sebagai salah satu input produksi dalam sektor perkebunan memegang peranan penting dalam menentukan produktivitas hasil perkebunan (Sudaryati, 2004).

Mubyarto (1984), menyatakan bahwa lahan merupakan salah satu faktor produksi sebagai pabriknya hasil pertanian yang memiliki peranan yang sangat besar terhadap usahatani. Luas atau sempitnya lahan yang digunakan dapat memengaruhi besar kecilnya produksi usahatani. Semakin luas lahan yang digunakan petani maka semakin besar produksi kopi yang dihasilkan. Luas lahan yang memadai dan didukung oleh tingkat kesuburan tanah yang baik, maka akan meningkatkan produksi kopi yang akan dihasilkan.

Jumlah tenaga kerja dengan variabel produksi kopi menunjukkan bahwa nilai $\mathrm{t}$ hitung sebesar 2,589, koefisien regresi sebesar 0,286 dan nilai probabilitas sebesar 0,013 , hal ini memiliki arti bahwa jumlah tenaga kerja berpengaruh positif dan signifikan terhadap produksi kopi, dan nilai t hitung sebesar 2,589 lebih besar dari $\mathrm{t}$ tabel sebesar 2,02269 sehingga dapat disimpulkan bahwa jumlah tenaga kerja berpengaruh signifikan terhadap produksi kopi. Hal ini berarti bahwa apabila tenaga kerja semakin banyak maka jumlah produksi kopi robusta di Desa Kertamandala akan semakin meningkat. Sejalan dengan hasil penelitian Risandewi (2013), Fatma (2011), Ratih dan Harmini (2012), hal ini bisa terjadi dikarenakan petani lebih cenderung untuk bekerja pada areal perkebunan sendiri dari pada bekerja pada petani pekebun lainnya, terutama pada musim panen.

Sebagian besar tenaga kerja merupakan keluarga dari petani sendiri yang terdiri atas suami, istri, dan anakanaknya. Biasanya mereka membantu mengangkut pupuk ke kebun, membantu memanen hasil pertanian, dan sebagainya. Kurang maksimalnya tenaga kerja 
disebabkan karena kurangnya penggunaan tenaga kerja upahan mengingat pada umumnya petani di lokasi penelitian memiliki lahan sendiri yang harus dikelola sendiri, namun kadang kala petani membayar tenaga kerja tambahan, misalnya dalam hal membantu memanen hasil pertanian

Umur tanaman dengan variabel produksi kopi menunjukkan bahwa nilai $\mathrm{t}$ hitung sebesar 3,691, koefisien regresi sebesar 0,574 dan nilai probabilitas sebesar 0,001, hal ini berarti bahwa umur tanaman berpengaruh positif dan signifikan terhadap produksi kopi, dan nilai t hitung sebesar 3,691 lebih besar dari t tabel sebesar 2,02269 sehingga dapat disimpulkan bahwa umur tanaman berpengaruh signifikan terhadap produksi kopi. Hal ini sejalan dengan hasil penelitian Fatma (2011), yang menunjukan adanya pengaruh nyata umur tanaman kopi terhadap jumlah produksi kopi. Dari hasil pengamatan di lapangan hal ini disebabkan karena umur pohon kopi di Desa Kertamandala berkisar 6 tahun sampai 15 tahun. Jumlah produksi kopi akan semakin meningkat dari tahun ke tahun, dan puncaknya setelah tanaman kopi berumur 9 tahun.

Jumlah pupuk dengan variabel produksi kopi menunjukkan bahwa nilai $\mathrm{t}$ hitung sebesar 2,513, koefisien regresi sebesar 0,198 dan probabilitas sebesar 0,016, hal ini berarti bahwa jumlah pupuk berpengaruh positif dan signifikan terhadap produksi kopi, dan nilai t hitung sebesar 2,513 lebih besar dari $\mathrm{t}$ tabel sesesar 2,02269 sehingga dapat disimpulkan bahwa jumlah pupuk berpengaruh signifikan terhadap produksi kopi. Hal ini sesuai dengan penelitian Risandewi (2013), Ratih dan Harmini (2012), yang menunjukan adanya pengaruh nyata jumlah pupuk terhadap produksi karena pupuk mampu memperbaiki pertumbuhan dan produktivitas tanaman kopi. Pemberian pupuk khususnya pupuk kandang mempunyai peranan besar dalam memperbaiki sifat fisik, kimia, biologi serta meningkatkan hara dalam tanah.

Dinas Pertanian telah mengeluarkan pedoman tingkat penggunaan pupuk per satuan luas secara teknis. Produktivitas per satuan lahan dapat menjadi berkurang dan produksi mengalami penurunan jika penggunaan pupuk tidak sesuai dosis.

\section{KESIMPULAN DAN SARAN}

\section{Kesimpulan}

Berdasarkan hasil penelitian, maka dapat ditarik kesimpulan baik secara simultan maupun parsial luas lahan, jumlah tenaga kerja, umur tanaman dan jumlah 
pupuk memengaruhi produksi kopi di Desa

Kertamandala Kecamatan Panjalu

\section{Saran}

1. Bagi para petani kopi, untuk meningkatkan produksi kopi robusta di Desa Kertamandala perlu dilakukan intensifikasi lahan, dan menambah jumlah tenaga kerja agar dapat menghasilkan produksi kopi robusta yang lebih tinggi.

2. Bagi Pemerintah Daerah Kabupaten Ciamis, khususnya dinas teknis seperti Dinas Pertanian dan Ketahanan Pangan untuk meningkatkan produksi kopi robusta di Desa Kertamandala maka perlu melakukan peningkatan luas lahan kopi yang ada, memberikan penyuluhan bagi petani dan tenaga kerja/buruh tani kopi agar setiap pemilik lahan ataupun buruh tani yang menggarap lahan kopi mampu lebih memahami cara menanam kopi dan menghasilkan kopi robusta dengan mutu dan kualitas yang baik.

\section{DAFTAR PUSTAKA}

Abdurrahman, M. dan Muhidin, S.A. 2011. Panduan Praktis Memahami Penelitian (Bidang SosialAdministrasi-Pendidikan). Bandung: CV Pustaka Setia.

Abimanyu, W., Hadi, S. dan Ridho, A.A. 2018. Studi Komparatif Usaha Perkebunan Kopi Robusta dan Kopi Arabika di Kecamatan Panti Kabupaten Jember. Jurnal Agribest,
02(01): 14-23.

Badan Penyuluhan Pertanian Kecamatan Panjalu. 2020. Laporan Tahunan. Panjalu.

Badan Pusat Statistik 2018. Provinsi Jawa Barat Dalam Angka. Bandung.

Dinas Pertanian Kabupaten Ciamis. 2019. Laporan Tahunan. Ciamis.

Fatma, Z. 2011. Analisis Fungsi Produksi dan Efisiensi Usahatani Kopi Rakyat di Aceh Tengah. Tesis. Program Pascasarjana Studi Ilmu Ekonomi Pertanian. IPB Bogor.

Isyanto, A.Y. 2012. Faktor-faktor yang Berpengaruh Terhadap Produksi pada Usahatani Padi di Kabupaten Ciamis. Cakrawala Galuh, 1(8): 1-8.

Isyariansyah, M.D., Sumarjono, D. dan Budiraharjo, K. 2018. Analisis Faktor-faktor Produksi yang Mempengaruhi Produksi Kopi Robusta di Kecamatan Sumowono Kabupaten Semarang. Jurnal Agrisocionomics, 2(1): 31-38.

Mubyarto. 1984. Pengantar Ekonomi Pertanian, Edisi 3. Jakarta: LP3ES.

Ratih, F dan Harmini. 2012. Efisiensi Teknis Usahatani Ubi Jalar di Desa Cikarawang Kabupaten Bogor Jawa Barat. Forum Agribisnis, 2(1): 17-32.

Risandewi, T. 2013. Analisis Efisiensi Kopi Robusta di Kabupaten Temanggung (Studi Kasus di Kecamatan Candiroto). Jurnal Litbang Provinsi Jawa Tengah, 11(1): 87-102.

Santoso, B. 2016. Pendugaan Fungsi Keuntungan dan Skala Usaha pada Usahatani Kopi Rakyat di Lampung. Jurnal Penelitian Agro Ekonomi, 6(1-2), 29-41.

Sudaryati, E. 2004. Faktor-Faktor yang Mempengaruhi Produksi Kopi Rakyat di Kabupaten Temanggung. Tesis. Program Pascasarjana Magister Ilmu Ekonomi dan Studi Pembangunan Universitas 
Jurnal Ilmiah Mahasiswa AGROINFO GALUH

Volume 7, Nomor 3, September 2020 : 625-633

Diponegoro.

Sugiyono. 2014. Metode Penelitian Pendidikan Pendekatan Kualitatif, Kuantitatif dan $R \& D$. Bandung:
Alfabeta.

Sukirno, S. 2005. Mikro Ekonomi Teori Pengantar. Edisi ketiga. Jakarta: Raja Grafindo Persada. 